\title{
Aspects of kerogen oxidative dissolution in subcritical water using oxygen from air
}

\author{
Kristiina Kaldas, Allan Niidu, Gert Preegel, Jaan Mihkel Uustalu, Kati \\ Muldma, Margus Lopp*
}

Laboratory of Industrial Chemistry, Department of Chemistry and Biotechnology, Tallinn University of Technology, Ehitajate tee 5, 19086 Tallinn, Estonia

Received 23.11.2020, accepted 23.07.2021, available online 10.09.2021

\begin{abstract}
Society's growing demands on everyday products and materials are increasingly difficult to meet in an environment that seeks to avoid petroleumbased processes. Instead of abandoning fossil materials altogether, more research should be done on their efficient and clean conversion. One option for this is the oxidative dissolution of kerogen in water under conditions that satisfy the subcritical range $\left(T=150-200{ }^{\circ} \mathrm{C}, \mathrm{pO} \mathrm{O}_{2}=0.5-4 \mathrm{MPa}\right)$. The resulting mixture contains a substantial amount of various aliphatic carboxylic and dicarboxylic acids. Both batch and semi-continuous processes were set up to find the main factors and optimal conditions for the kerogen dissolution process. The rate of transformation of organic carbon to dissolved organic compounds was mainly influenced by elevated temperature and oxygen partial pressure. To obtain high yields of organic carbon dissolution and to avoid the formation of excess $\mathrm{CO}_{2}$, the oxidation of kerogen should be carried out fast $(<1 \mathrm{~h})$ and under high oxygen pressure. By employing a temperature of $175{ }^{\circ} \mathrm{C}$ and $\mathrm{O}_{2}$ pressure of $2 \mathrm{MPa}$, over $65 \%$ of the initial organic carbon dissolves in about one hour. Prolonged reaction times or harsher oxidation conditions resulted in a rapid degradation of dissolved matter and also of the valuable products formed. The organic matter content of the initial oil shale had a direct effect on the further degradation of dicarboxylic acid and consequently on the overall yield. The suitability of using a trickle-bed reactor for kerogen dissolution is discussed in detail on the basis of experimental results.
\end{abstract}

Keywords: kerogen dissolution, wet air oxidation, dicarboxylic acids.

\footnotetext{
* Corresponding author: e-mail margus.lopp@taltech.ee

(C) 2021 Authors. This is an Open Access article distributed under the terms and conditions of the Creative Commons Attribution-NonCommercial 4.0 International License (http://creativecommons.org/licenses/by-nc/4.0/).
} 


\section{Introduction}

Development of sustainable processes to valorize the existing raw organic materials, including organic wastes, has become an essential target for the chemical industry. Estonian oil shale, a sedimentary rock from the Ordovician era, called Kukersite [1], is used for production of electricity and crude oil. The commercial value of organic compounds from oil shale organic matter (kerogen) may be several times higher than that from the current use of oil shale (e.g. shale oil and phenols). The search for alternative approaches to a more efficient utilization of kerogen should be based on knowledge of its structure. According to Blokker et al. [2], Lille et al. [3] and Lille [4] the heterogeneous kerogen matrix consists of building blocks composed of large alkyl and alkenyl fragments joined by resorcinol units. In the selection of a suitable process for dissolving the organic matter of Kukersite, parallels with lignin-carbohydrate complexes can be drawn, among which oxidative depolymerization methods have been reported [5-7]. The main monomeric products separable from these complex organic structures are carboxylic acids and their analogs. These compounds can serve as starting materials for both the chemical and materials industries [8-11]. The commercial value of organic compounds from oil shale organic matter (kerogen) may be several times higher than that from the current use of oil shale (e.g. shale oil and phenols) $[12,13]$.

It has been shown previously that up to $40 \%$ of the kerogen in Kukersite is convertible to a mixture of aliphatic dicarboxylic acids (DCAs) by using oxidative conditions $[13,14]$. Various processes, such as oxidation with nitric acid $[13,15-17]$ or potassium permanganate [18-20], as well as use of a continuous flow of air fed through basic aqueous solutions [21-23] have been examined. Unfortunately, most of the cited works date back more than 50 years, and thus there is a lack of information on whether these applications are feasible in a modern industrial environment.

Kaldas et al. [24] have reported that oil shale could be dissolved via oxidative degradation using a wet air oxidation (WAO) process. The main advantage of the WAO method compared to conventional petrochemical processes is a shorter route from organic sediments to chemicals, lower temperatures, use of water as a solvent and air as an oxidant. As the WAO process is widely used in wastewater treatment, technical solutions are readily available [25-27]. It has been demonstrated that by use of the WAO process at $175^{\circ} \mathrm{C}$ for $3 \mathrm{~h}$ the yield of water soluble chemical compounds can be up to $50 \%$ of the initial kerogen content [24]. Moreover, 20-30\% of these soluble compounds represent aliphatic dicarboxylic acids. Beside Estonian Kukersite, Jordanian and Green River (USA) shales behave similarly.

In the present work, the main focus was on determining the distribution of organic carbon between solid, liquid and gaseous phases throughout the reaction period rather than on the yield of DCA. Kukersite was subjected to 
the WAO process in wider pressure and substrate concentration ranges than in the work by Kaldas et al. [24], namely $0.5-4 \mathrm{MPa}$ and $2.5-40 \mathrm{~g} / \mathrm{L}$, and at temperatures of $155-185{ }^{\circ} \mathrm{C}$ in $500 \mathrm{ml}$ batch reactors. The aim was to establish the optimal conditions for obtaining a maximum yield of organic carbon in liquid phase by avoiding its over-oxidation to $\mathrm{CO}_{2}$. Examples and a discussion of scalability and use of semi-continuous processes are presented. In the final part of the work the formation of DCAs is discussed with respect to their secondary destruction in the course of oxidation.

\section{Experimental}

Oil shale (kerogen content $\sim 45 \%$; K-45) and its concentrate (kerogen content $\sim 70 \%$; K-70) were obtained from the Oil Shale Competence Centre Estonia in Kohtla-Järve. The studied samples, K-70 and K-45, had particle sizes $<45 \mu \mathrm{m}$ and $<90 \mu \mathrm{m}$, respectively. The elemental analysis results for these oil shale samples are given in Table 1 and additional information on their mineral contents can be found in the research by Kaldas et al. [24].

Table 1. The chemical composition of oil shale samples, $\mathrm{wt}^{\mathrm{a}}$

\begin{tabular}{|c|c|c|c|c|c|c|c|}
\hline Sample & C & H & N & S & O & TIC & TOC \\
\hline K-70 & 57.8 & 6.7 & 0.16 & 0.7 & 19.1 & 1.3 & 56.5 \\
K-45 & 38.4 & 4.4 & 0.12 & 1.7 & 17.7 & 3.2 & 35.1 \\
\hline
\end{tabular}

${ }^{\text {a }} \mathrm{TIC}$ - total inorganic carbon; TOC - total organic carbon

For WAO experiments the same protocol was followed as previously [24]. Large scale experiments were carried out in a $500 \mathrm{~mL}$ stainless steel pressure reactor (4575A, Parr Instrument Company, Moline, Il, USA) having similar properties as the $100 \mathrm{ml}$ reactor used earlier. Briefly, a specified amount of oil shale concentrate K-70 was weighed into the reactor together with distilled water. The reactor was pressurized up to a selected level with oxygencontaining gas, heated to the desired temperature and stirred at a speed of $1000 \mathrm{rpm}$. Three different gas mixtures were used: synthetic air $\left(21 \% \mathrm{O}_{2}\right.$ and $\left.79 \% \mathrm{~N}_{2}\right)$, pure oxygen $\left(100 \% \mathrm{O}_{2}\right)$ and a $50 / 50$ mixture of $\mathrm{O}_{2}$ and $\mathrm{N}_{2}$. The time zero $\left(\mathrm{t}_{0}\right)$ of the reaction was taken as the point when the reaction temperature reached $5{ }^{\circ} \mathrm{C}$ below the set point. At the end of the reaction, the reactor was cooled and depressurized, the evolved gas was collected, and analyzed using gas chromatography with a thermal conductivity detector (GC-TCD). The unreacted solid residue was separated by centrifugation, dried at $105{ }^{\circ} \mathrm{C}$ for $24 \mathrm{~h}$ and weighed. These samples were then subjected to elemental analysis. The supernatant was collected separately, water was evaporated and the resulting sample (dissolved matter) was sent for elemental analysis. For determining the content of DCAs, a portion of the sample was esterified and analyzed as 
DCA dimethyl esters (DME, C4-C10) by using gas chromatography with a flame ionization detector (GC-FID).

The distribution of carbon between the unreacted kerogen and dissolved organics phase was calculated using the carbon concentrations from elemental analysis times the weight of the materials in these phases, divided by the initial carbon content in oil shale (Eq.). Elemental analysis was performed on a Vario MACRO CHNS Cube analyzer and a rapid OXY Cube for O. The measured $\mathrm{CO}_{2}$ and $\mathrm{O}_{2}$ levels in the gas phase provided a measure of the total extent of oxidation. Gas analysis was carried out with a Shimadzu GC-2014 gas chromatograph with a sample valve system, which made it possible to determine all of the gases of interest in a single run. From the measured $\mathrm{CO}_{2}$ values, the content of gasified carbon was determined. However, depending on the operating conditions, complete carbon mass balance was not always achieved. The imbalance was mainly caused by the fraction of dissolved lowmolecular-weight organic carbon-containing compounds that was lost during the evaporation step, as also reported earlier [24]:

$$
C, \%=\frac{\text { post- oxidation } \mathrm{TOC}, \% \times \text { weighed residue, } \mathrm{mg}}{\text { initial TOC, } \% \times \text { initial oil shale, } \mathrm{mg}}
$$

For DCA determination, the esterified sample of the dissolved organics was qualitatively and quantitatively analyzed with a Shimadzu GC-2010 FID gas chromatograph using a $30 \mathrm{~m}$ polyimide-coated fused silica Zebron ZB-5HT Inferno $(0.25 \mu \mathrm{m})$ capillary column programmed at $10{ }^{\circ} \mathrm{C} / \mathrm{min}$ from $50{ }^{\circ} \mathrm{C}$ (with a $4 \mathrm{~min}$ isothermal hold) to $300{ }^{\circ} \mathrm{C}$ (with a $3 \mathrm{~min}$ isothermal hold). For further details of the analysis method used, please refer to the earlier publication [24].

\section{Results and discussion}

\subsection{Time-dependent dissolution of Kukersite kerogen}

The distribution of organic carbon between kerogen, dissolved product in the water phase and $\mathrm{CO}_{2}$ in the gas phase as a function of reaction time is shown in Figure 1 along with the decrease in $\mathrm{O}_{2}$. Oil shale at concentrations of $20-40 \mathrm{~g} / \mathrm{L}$ in water was treated at an initial pressure of synthetic air of $4 \mathrm{MPa}\left(\mathrm{pO}_{2} 0.84 \mathrm{MPa}\right)$, or a $50 / 50$ mixture of $\mathrm{O}_{2} / \mathrm{N}_{2}\left(\mathrm{pO}_{2} 2 \mathrm{MPa}\right)$ at $175^{\circ} \mathrm{C}$. The results obtained confirmed the conclusion of the previous research [24] that the kerogen dissolution reaction is completed within $3 \mathrm{~h}$ (Figs. 1a, 1c). At low kerogen concentrations relative to oxygen, the dissolution process stopped due to depletion of kerogen. The oxidation process, however, continued with oxidation of the dissolved organics to $\mathrm{CO}_{2}$ at a different reaction rate. When the oxidant was added to a nearly equimolar amount of 
(a)

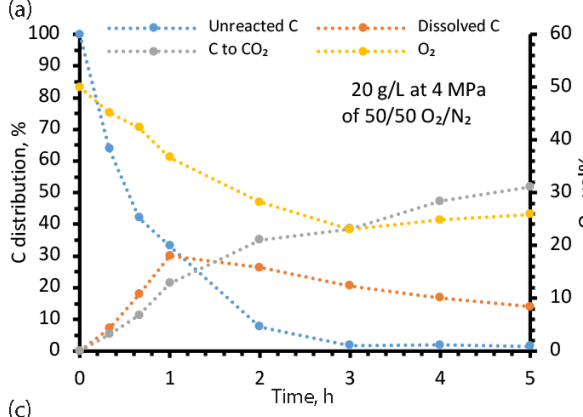

(c)

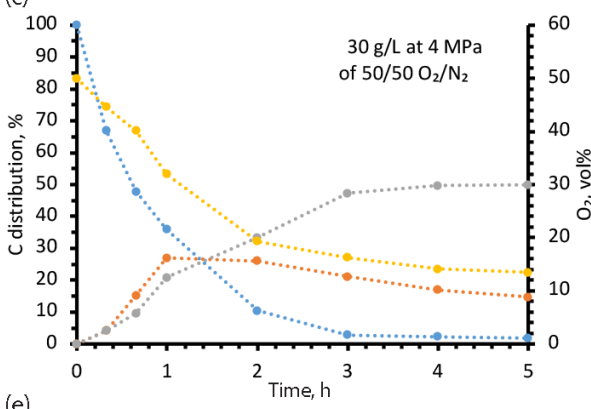

(e)

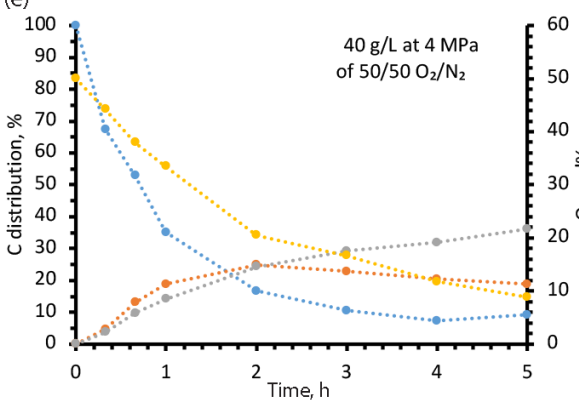

(b)

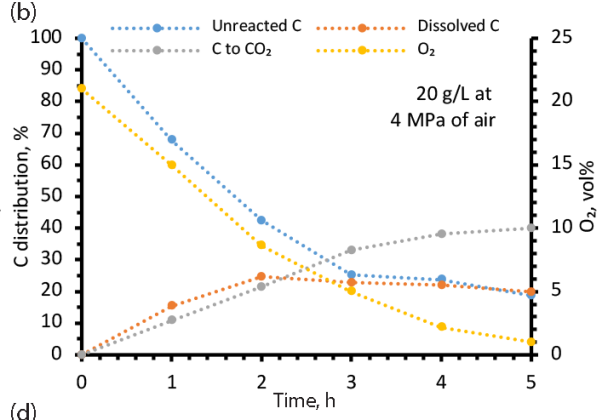

(d)

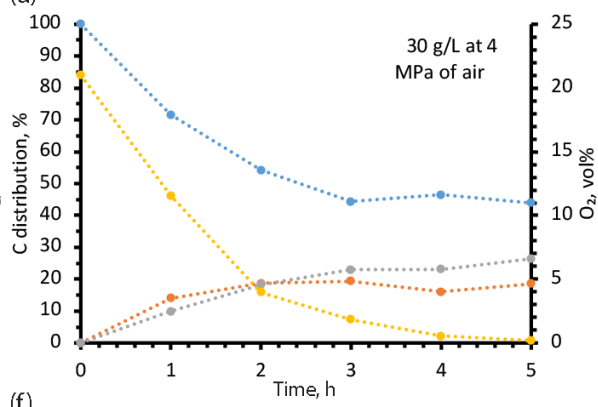

(f)

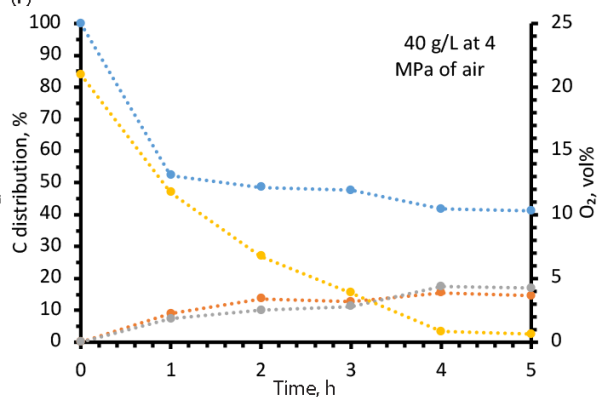

Fig. 1. The effect of oil shale concentration in time dependent experiments at $175^{\circ} \mathrm{C}$ on the distribution of organic carbon between solid (unreacted C), dissolved (dissolved C) and gaseous $\left(\mathrm{C}\right.$ to $\left.\mathrm{CO}_{2}\right)$ forms.

organic carbon (Figs. 1b, 1e), a continuous decrease in the organic carbon content of the solid kerogen and an increase in the carbon content of the gas phase were observed throughout the entire reaction period. At high kerogen concentrations compared to oxygen, the oxidation process stopped because of depletion of oxygen (Figs. 1d, 1f). When synthetic air was used as an oxidant, the oxygen deficiency occurred already at an early stage of oxidation.

Carbon distribution data show that the dissolution of kerogen carbon paralleled the formation of $\mathrm{CO}_{2}$. Even after a complete conversion of the initial organic carbon of kerogen, a considerable $\mathrm{CO}_{2}$ formation occurred. As long as oxygen was still present in the medium, further oxidative reactions 


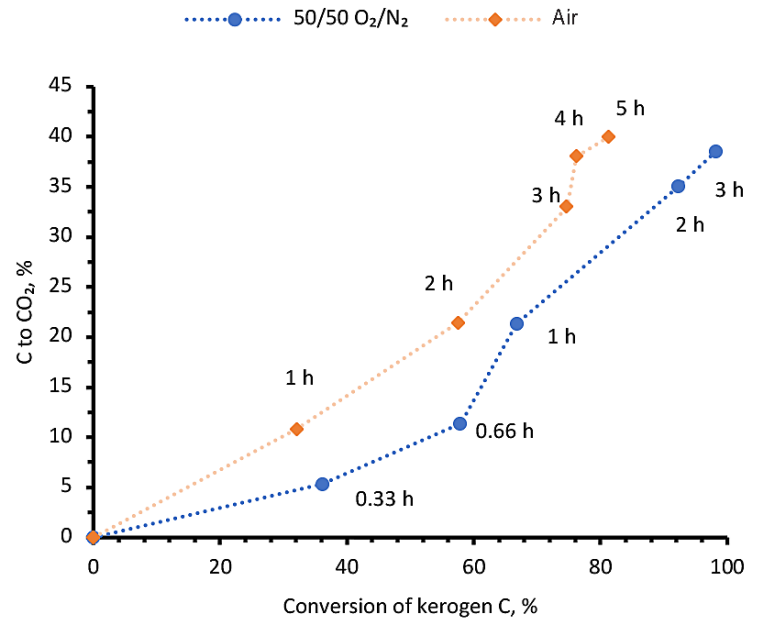

Fig. 2. $\mathrm{CO}_{2}$ evolution per organic carbon conversion at $175^{\circ} \mathrm{C}$ and $4 \mathrm{MPa}$ with $20 \mathrm{~g} / \mathrm{L}$ of K-70.

took place, as evidenced by the increase in $\mathrm{CO}_{2}$ during the 4th and 5 th hours of the reaction (Fig. 1a). The experimental data strongly suggest that in the long run and in the excess of oxygen the oxidation will continue until all organic carbon is converted to $\mathrm{CO}_{2}$.

Comparing the conversion of kerogen carbon with the formation of $\mathrm{CO}_{2}$ at different oxygen concentrations, it can be seen that at higher oxygen concentration less $\mathrm{CO}_{2}$ and more dissolved organic compounds were generated (Fig. 2). At short reaction times, the oxidation of dissolved organics had a smaller contribution to the amount of evolved $\mathrm{CO}_{2}$. This suggests that the production of dissolved organic compounds should be conducted in a short period of time.

The experimental data show that the mechanism of kerogen disintegration is similar to a common WAO mechanism, in which the oxidation of organic compounds proceeds in two steps [28-30]. With oil shale kerogen, the first reaction step is the oxidation of the resorcinol entities of kerogen [2]. Within that time, the carbon linkages between resorcinol units become water-soluble, while the rest of the resorcinol is rapidly oxidized to $\mathrm{CO}_{2}$. It can be assumed that this step is predominant during the first hour of kerogen oxidation. The second reaction step represents a further oxidation of the dissolved material, with additional $\mathrm{CO}_{2}$ release. Further discussion, additional experiments and calculations are required to prove this suggestion. 


\subsection{The effect of temperature and pressure on Kukersite kerogen dissolution}

To investigate the influence of pressure and temperature on the distribution of organic carbon, oil shale K-70 at a low concentration $(2.5 \mathrm{~g} / \mathrm{L}$, to ensure a sufficient oxygen concentration throughout the experiment) was treated with pure oxygen. The results obtained in the "one-hour" experiments are shown in Figure 3. It can be seen that the effect of pressure was minimal at the lowest temperature $\left(150{ }^{\circ} \mathrm{C}\right)$. The conversion of kerogen followed a nearly linear dependence on the pressure of the oxidant at temperatures of $165-175{ }^{\circ} \mathrm{C}$, showing an increase in the effective amount of oxidant relative to kerogen. At the highest temperature, the linearity from the oxidant pressure abated as the amount of organic carbon in the reaction mixture decreased rapidly: at $185{ }^{\circ} \mathrm{C}$ and $0.5 \mathrm{MPa}$, a quarter of the initial organic carbon had already been converted. At pressures below the saturated vapor pressure $(0.9 \mathrm{MPa}$ at $\left.175{ }^{\circ} \mathrm{C}[31]\right)$, the conditions fall out of the subcritical region, leading to other degradation pathways that were not studied in this work.

It is notable that increasing the temperatures above $175^{\circ} \mathrm{C}$ did not increase the amount of carbon in the dissolved organic compounds. Figure 3 shows that the formation of dissolved organic carbon was in equilibrium with their oxidation to $\mathrm{CO}_{2}$. Thus, it is evident that during kerogen dissolution at subcritical conditions, the formation of $\mathrm{CO}_{2}$ was unavoidable.

The data also showed that the loss in the carbon material balance increased with temperature. This could be explained by the increasing number of low-

(a)

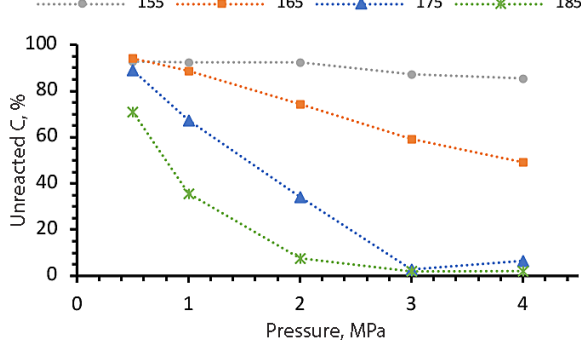

(b)

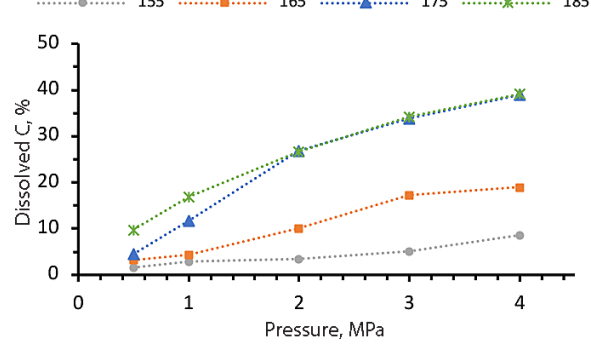

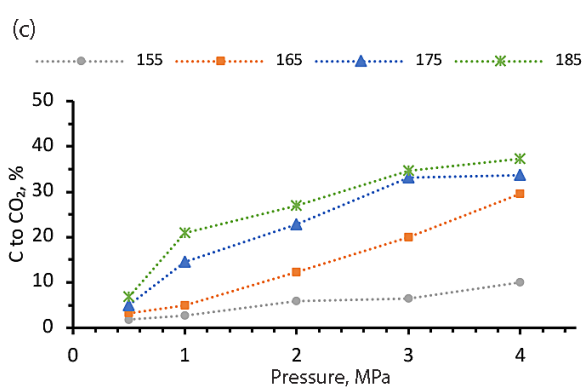

Fig. 3. Time- and pressure-dependent experiments with $2.5 \mathrm{~g} / \mathrm{L} \mathrm{K}-70$ and $100 \% \mathrm{O}_{2}$ for $1 \mathrm{~h}$. 
molecular-weight compounds (volatile intermediates) formed in parallel, i.e. the number of compounds lost during the evaporation process increased with temperature, indicating that temperatures higher than $185^{\circ} \mathrm{C}$ should be avoided since over-oxidation processes of already dissolved organics prevailed. It can be concluded that the optimum operating conditions for an efficient dissolution of kerogen were the following: temperature $175-185^{\circ} \mathrm{C}$ and $\mathrm{O}_{2}$ partial pressure 2-3 $\mathrm{MPa}$.

By considering the results of all oxidation experiments conducted at $175^{\circ} \mathrm{C}$ and $\mathrm{pO}_{2}$ of $2 \mathrm{MPa}$ with different kerogen concentrations, the oxygen consumption during the first hour was calculated. At an initial $\mathrm{O} / \mathrm{C}$ ratio from $20: 1$ to $1.5: 1$, the consumption was approximately $0.8 \mathrm{~mol}$ of $\mathrm{O}_{2}$ per reacted carbon, suggesting that the oxidation process was independent of oxygen concentration within these limits and the composition of the dissolved organics from this step was similar.

\subsection{Semi-continuous process for dissolving Kukersite}

Experiments on dissolving kerogen in a semi-continuous mode were performed in a trickle-bed reactor ( made of stainless steel, $d_{\text {inner }}=15.6 \mathrm{~mm}$, length $=600 \mathrm{~mm}$ ). Thus, $10 \mathrm{~g}$ of oil shale (K-70) was packed in layers with quartz wool and sand $(40 \mathrm{~g}, \mathrm{~d} \geq 90 \mu \mathrm{m})$. The upper part of the reactor was filled with glass beads $(\mathrm{d}=3 \mathrm{~mm}, 70 \mathrm{~g})$ to ensure a uniform distribution of the liquid in the reactor (Fig. 4).

The continuous removal of dissolved kerogen from the reaction medium was expected to minimize the contact time of the dissolved kerogen with oxygen in the reactor and prevent over-oxidation. Various temperatures $\left(150-200{ }^{\circ} \mathrm{C}\right)$, air flow rates $(20-400 \mathrm{ml} / \mathrm{min})$ and water flow rates $(0.3-0.9 \mathrm{ml} / \mathrm{min})$ were tested. Liquid and gas samples were collected at $15 \mathrm{~min}$ intervals.

As seen from Table 2, an increase in temperature and the ratio of oxygen to oil shale afforded a higher conversion of organic carbon. This means that the same trends observed above for a batch process also applied to a semicontinuous process. The overall conversion rate of kerogen, however, was significantly lower than that in batch reactors. Moreover, the amount of $\mathrm{CO}_{2}$ emitted per organic carbon consumed in the reaction did not decrease compared to the experiments above. The amount of dissolved organics obtained (measured as esterified product) was also considerably lower than expected. The distribution of DCAs in the dissolved product showed a preference for short-chain DCAs (represented as the ratio of high-molecular-weight DCA to total DCA, C7-C10/DCA, Table 2), similarly to that observed in batch reactors [24]. A significant drawback that arose during the operation of the trickle-bed reactor was the local overheating of the oil shale bed. This led to local thermal decomposition processes and a sudden rise in the observed $\mathrm{CO}_{2}$ 


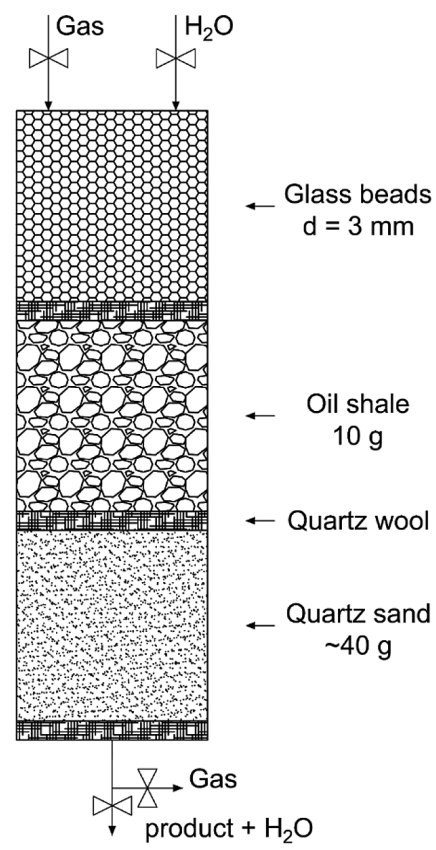

Fig. 4. The scheme of the trickle-bed reactor used.

values, as can be seen from the experiments carried out at a water flow rate of $0.3 \mathrm{ml} / \mathrm{min}$ (Table 2, exp 4 and exp 7). Therefore, the water flow rate through the reactor was kept high, which resulted in an overdiluted product and made the subsequent product isolation time and energy consuming.

In an experiment where a $10 \%$ acetic acid solution was used instead of distilled water for faster kerogen conversion [24], the product formation profile (Fig. 5) was not substantially different from that of the other experiments (see

(a)

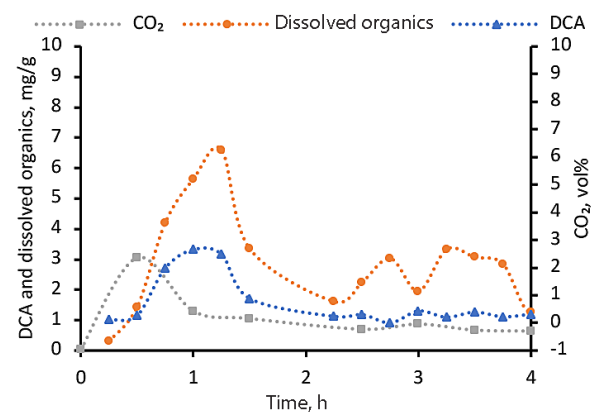

(b)

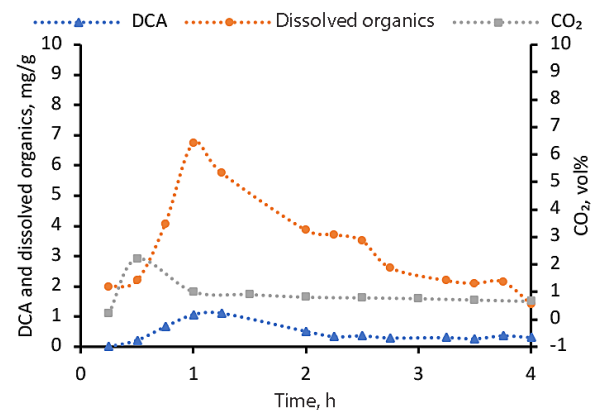

Fig. 5. K-70 dissolution in the trickle-bed reactor: (a) corresponds to exp 2 and (b) to exp 6 in Table 2. 
Table 2. Results of K-70 oxidation in the trickle-bed reactor

\begin{tabular}{|c|c|c|c|c|c|c|c|c|c|}
\hline 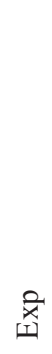 & $\begin{array}{l}\stackrel{0}{0} \\
\mapsto\end{array}$ & 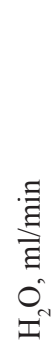 & 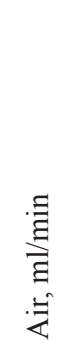 & 番 & 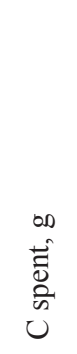 & 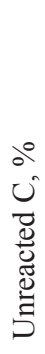 & $\begin{array}{l}0_{0}^{0} \\
0^{2} \\
0 \\
0 \\
0 \\
0\end{array}$ & 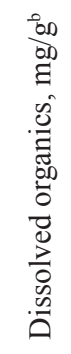 & $\begin{array}{l}0^{\circ} \\
\mathbb{e} \\
0 \\
0 \\
0 \\
0 \\
0 \\
0 \\
0\end{array}$ \\
\hline 1 & 150 & 0.6 & 400 & 4 & 1.08 & 82 & 17 & 37.0 & 24 \\
\hline $2^{c}$ & 175 & 0.6 & 400 & 5 & 3.18 & 50 & 19 & 58.5 & 8 \\
\hline 3 & 175 & 0.6 & 100 & 4 & 1.43 & 78 & 24 & 16.2 & 12 \\
\hline 4 & 175 & 0.3 & 100 & 4 & 1.31 & 78 & 38 & 23.6 & n.d \\
\hline 5 & 175 & 0.9 & 20 & 8 & 0.79 & 87 & 33 & 31.6 & n.d \\
\hline $6^{c}$ & 200 & 0.6 & 400 & 4 & 2.88 & 52 & 22 & 45.7 & n.d \\
\hline 7 & 200 & 0.3 & 100 & 4 & 1.24 & 79 & 57 & 18.6 & 13 \\
\hline
\end{tabular}

${ }^{\mathrm{a}}$ on the basis of spent carbon; ${ }^{\mathrm{b}}$ on the basis of initial oil shale $(10 \mathrm{~g}) ;{ }^{\mathrm{c}} 10 \%$ acetic acid solution was used instead of pure water. Abbreviation: Exp - experiment.

Table 2, exp 2 and exp 6). The process proceeded with two different reaction rates - the fast initial step and the subsequent slow period. Based on the structure of kerogen $[2,3]$, it may be suggested that the active groups on the surface of kerogen react first and then mass transfer becomes a limiting factor driving the reaction rate down. It was concluded that the used trickle-bed setup was not applicable as a base of this process.

\subsection{Further valorization of dissolved organics}

The dissolved kerogen organics sample contained $\sim 20-30 \%$ of DCAs on average. The rest was a mixture of monocarboxylic acids, branched and polycarboxylic acids, alcohols and ethers with various carbon skeletons (for more details, see [24]). Fractional distillation under the reduced pressure of nonderivatized DCAs directly from this mixture was unsuccessful due to the relatively high boiling points of carboxylic acids. Only the DCAs with the lowest boiling points (C4 and C5) were separable by distillation.

In order to evaluate whether the amount of DCAs would increase with additional oxidation, the mixture from the WAO process (free of inorganic salts) was further oxidized with a $4 \mathrm{MPa} \mathrm{O}_{2} / \mathrm{N}_{2}$ mixture at $175^{\circ} \mathrm{C}$ for 3 hours in the presence of $40 \mathrm{wt} \% \mathrm{KOH}$ or $\mathrm{K}_{2} \mathrm{CO}_{3}$ to increase the solubility of the 
isolated organics in the reaction medium. We found that the amount of DCAs increased by $30 \%$ of their initial value, while the total amount of dissolved organics decreased by more than $50 \%$ due to the additional $\mathrm{CO}_{2}$ formation. The decomposition of dissolved organics to $\mathrm{CO}_{2}$ was too extensive to consider the uncatalyzed WAO process in an alkaline medium as a feasible route to increase the DCA yield. To prove that the dissolved organics have the potential to yield additional DCA, the isolated dissolved organics were subjected to oxidation using nitric acid as an oxidant [17]. Applying $5 \mathrm{ml}$ of $65 \% \mathrm{HNO}_{3}$ per $1 \mathrm{~g}$ of dissolved organics at $80{ }^{\circ} \mathrm{C}$ for 3 hours, the amount of DCAs in the product increased by $125 \%$. As shown in Figure 6 , the product contained less isomeric DCAs after nitric acid oxidation. The result proves that a substantial part of the dissolved organics can be converted into DCAs, which increases the value of the product.

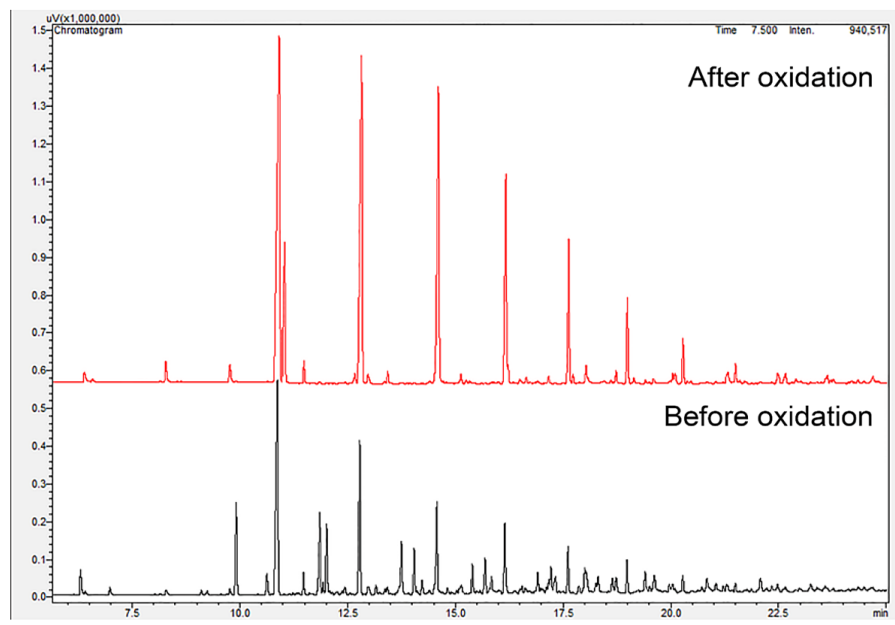

Fig. 6. GC-FID chromatogram of solubilized organics before and after the $\mathrm{HNO}_{3}$ oxidation.

\subsection{DCA destruction in the presence of oil shale}

It has been previously shown that the distribution of DCAs in the product is affected by the initial kerogen concentration of oil shale. Thus, when a native oil shale with a kerogen concentration of $45 \%$ (K-45) was oxidized, the total DCA fraction contained up to $40 \%$ of long-chain DCAs (C6-C10). For K-70 and K-90, the amount of C6-C10 DCAs was $14 \%$ and 7\%, respectively [24]. It has also been demonstrated that pure DCAs are relatively stable in water up to $175^{\circ} \mathrm{C}$ or higher, but the presence of bases or organic co-oxidants induces their decomposition [32]. Therefore, the decomposition of the formed products is an essential factor when adapting the WAO process to oil shale to obtain DCA. 
To understand the catalytic effect of oil shale and its components on DCA decomposition, we conducted experiments in which the stability of long-chain DCAs was monitored at WAO conditions. Thus, each dicarboxylic acid in the C6-C10 range was weighed into a reactor together with oil shale and water, and its recovered amount was measured after stirring at $175^{\circ} \mathrm{C}$, with $4 \mathrm{MPa}$ of $\mathrm{O}_{2} / \mathrm{N}_{2}(50 / 50)$ for $3 \mathrm{~h}$. The obtained value of each DCA was corrected with an average value of DCA obtained from oil shale in these conditions. The data in Table 3 reveal that all oil shale concentrates affected DCA decomposition. The oil shale concentrate with the highest organic matter content (K-90) affected the decomposition of DCA the most, and no long-chain DCAs (C9-C10) were left after a $3 \mathrm{~h}$ time (Table 3, exps 4-6). It is noticeable that the mineral part of oil shale (mineral ash from previous oxidation - "ox. ash" and ash from electrostatic filters of oil shale power station - "ESP ash") hindered DCA decomposition in comparison with "no additive" cases (Table 3, exps 1-3). On the other hand, in the presence of oil shale, selected inorganic salts or bases did not reduce DCA decomposition significantly (2-7\% increase in recovery;

Table 3. The effect of additives on DCA (C6-C10) decomposition in the WAO process $^{\mathrm{a}}$

\begin{tabular}{|c|c|c|c|c|c|c|c|}
\hline Exp & Additive & $\begin{array}{c}\text { Overall } \\
\text { recovery, \% }\end{array}$ & C6 & C7 & $\mathrm{C} 8$ & C9 & $\mathrm{C} 10$ \\
\hline 1 & - & 95 & 100 & 98 & 96 & 92 & 89 \\
\hline 2 & ESP ash & 97 & 96 & 96 & 95 & 97 & 100 \\
\hline 3 & Ox. ash & 98 & 99 & 99 & 99 & 98 & 97 \\
\hline 4 & K-45 & 40 & 70 & 54 & 35 & 23 & 16 \\
\hline 5 & $\mathrm{~K}-70$ & 30 & 74 & 50 & 18 & 6 & 2 \\
\hline 6 & K-90 & 22 & 76 & 31 & 4 & 0 & 0 \\
\hline 7 & $\mathrm{~K}-70+\mathrm{Ca}(\mathrm{OH})_{2}$ & 47 & 73 & 60 & 43 & 31 & 27 \\
\hline 8 & $\mathrm{~K}-70+\mathrm{K}_{2} \mathrm{CO}_{3}$ & 35 & 72 & 44 & 29 & 18 & 11 \\
\hline 9 & $\mathrm{~K}-70+\mathrm{CaCO}_{3}$ & 34 & 64 & 46 & 28 & 18 & 13 \\
\hline 10 & $\mathrm{~K}-70+\mathrm{CH}_{3} \mathrm{COOH}$ & 21 & 58 & 27 & 15 & 2 & 0 \\
\hline 11 & $\mathrm{~K}-70+5$-Me-resorcinol & 13 & 43 & 17 & 3 & 2 & 1 \\
\hline 12 & $\mathrm{~K}-45+\mathrm{K}_{2} \mathrm{CO}_{3}$ & 45 & 75 & 55 & 41 & 30 & 23 \\
\hline 13 & $\mathrm{~K}-45+\mathrm{CaCO}_{3}$ & 36 & 62 & 46 & 31 & 22 & 16 \\
\hline 14 & $\mathrm{~K}-45+\mathrm{CH}_{3} \mathrm{COOH}$ & 33 & 77 & 49 & 25 & 11 & 3 \\
\hline 15 & $\mathrm{~K}-45+\mathrm{KOH}$ & 32 & 62 & 41 & 27 & 18 & 12 \\
\hline
\end{tabular}

a Reaction conditions: $\mathrm{T}=175{ }^{\circ} \mathrm{C}, \mathrm{P}=4 \mathrm{MPa}$ of the $50 / 50 \mathrm{O}_{2} / \mathrm{N}_{2}$ mixture, time $=3 \mathrm{~h}$, oil shale or its concentrate in $\mathrm{c}=20 \mathrm{~g} / \mathrm{L}$. * Ox. ash - ash separated after WAO experiment; ESP ash - fly ash from electrostatic precipitator filters of oil shale power station. 
Table 3, exps 7-9, 12-15). We suggest that the high reactivity of DCA in the WAO process is due to the co-oxidation by some kerogen components. As mentioned before, the oxidative decomposition of kerogen is initiated by phenol-type resorcinol moieties [2]. Indeed, the addition of radical generating compounds such as 5-Me-resorcinol substantially increased the decomposition of DCAs (Table 3, exp 11), meaning that this process could have been caused by the presence of resorcinol units in kerogen. Accordingly, the decomposition rate of DCAs is accelerated when oil shale with high organic content and thereby with high resorcinol content is used. This also explains why the final distribution of chain lengths of DCAs observed after the WAO process does not reflect the actual lengths of the aliphatic subunits in the kerogen.

All this makes the choice of optimal conditions for an effective WAO process very important in order to minimize the degradation of the product during the dissolution of kerogen.

\section{Conclusions}

The oxidation of kerogen to water-soluble organic compounds that can be directly used or upgraded to value-added products should be considered as an alternative direction for improving the oil shale industry. The experimental results of kerogen dissolution under oxidative conditions in subcritical water showed that over $65 \%$ of the organic carbon dissolved in about 1 hour at a temperature of $175^{\circ} \mathrm{C}$ and a pressure of $\mathrm{O}_{2}$ of $2 \mathrm{MPa}$.

A direct dependence of kerogen transformation on the oxidant amount at different oil shale concentrations was observed. To avoid excessive oxidation of dissolved organics and high $\mathrm{CO}_{2}$ formation, the kerogen oxidation process should be conducted with the shortest possible reaction times with excess oxygen. It was demonstrated that the minimum working temperature of the process is $165^{\circ} \mathrm{C}$.

The decomposition of dicarboxylic acids, the most valuable products of dissolved organics, strongly depends on the oil shale organic matter content. Oil shale with the highest degree of kerogen induced the decomposition of DCAs the most. It was also shown that the amount of DCAs in the mixture of dissolved organics can be doubled by additional oxidation with nitric acid.

The application of a semi-continuous process using a trickle-bed reactor did not improve the yield of dissolved organics and the method was considered unsuitable for kerogen dissolution.

\section{Acknowledgments}

The authors thank the following institutions for supporting this work: the Centre of Excellence in Molecular Cell Engineering (Grant No. 2014- 
2020.4.01.15-0013), the Estonian Ministry of Education and Research (Grant No. PRG657), and the European Regional Development Fund (Grant No. 2014-2020.4.02.16-0050). We acknowledge Kerogen Ltd. for financial support and Alexela Group Ltd. for technical support. We thank the Laboratory of the Department of Energy Technology in TalTech for carrying out compositional analysis and Åbo Akademi University for setting up the trickle-bed reactor.

\section{REFERENCES}

1. Derenne, S., $\quad$ Largeau, C., $\quad$ Casadevall, E., $\quad$ Sinninghe Damsté, J. S., Tegelaar, E. W., de Leeuw, J. W. Characterization of Estonian Kukersite by spectroscopy and pyrolysis: Evidence for abundant alkyl phenolic moieties in an Ordovician, marine, type II/I kerogen. Org. Geochem., 1990, 16(4-6), 873-888.

2. Blokker, P., Van Bergen, P., Pancost, R., Collinson, M. E., De Leeuw, J. W., Sinninghe Damste, J. S. The chemical structure of Gloeocapsomorpha prisca microfossils: implications for their origin. Geochim. Cosmochim. Acta, 2001, 65(6), 885-900.

3. Lille, Ü., Heinmaa, I., Pehk, T. Molecular model of Estonian kukersite kerogen evaluated by ${ }^{13} \mathrm{C}$ MAS NMR spectra. Fuel, 2003, 82(7), 799-804.

4. Lille, Ü. Current knowledge on the origin and structure of Estonian kukersite kerogen. Oil Shale, 2003, 20(3), 253-263.

5. Behling, R., Valange, S., Chatel, G. Heterogeneous catalytic oxidation for lignin valorization into valuable chemicals: What results? What limitations? What trends? Green Chem., 2016, 18(7), 1839-1854.

6. Demesa, A. G., Laari, A., Turunen, I., Sillanpa, M. Alkaline partial wet oxidation of lignin for the production of carboxylic acids. Chem. Eng. Technol., 2015, 38(12), 2270-2278.

7. Kindsigo, M., Kallas, J. Degradation of lignins by wet oxidation: model water solutions. Proc. Est. Acad. Sci. Chem., 2006, 55(3), 132-144.

8. Cherubini, F., Stromman, A. H. Chemicals from lignocellulosic biomass: opportunities, perspectives, and potential of biorefinery systems. Biofuel. Bioprod. Bior., 2011, 5(5), 548-561.

9. Wang, Z., Yan, J., Wang, T., Zai, Y., Qiu, L., Wang, Q. Fabrication and properties of a bio-based biodegradable thermoplastic polyurethane elastomer. Polymers, 2019, 11(7), 1-13.

10. Cornils, B., Lappe, P. Dicarboxylic acids, aliphatic. In: Ullmann's Encyclopedia of Industrial Chemistry, Wiley-VCH Verlag GmbH \& Co. KGaA, 2000.

11. Yuan, W.-G., Liu, G.-L., Huang, C., Li, Y.-D., Zeng, J.-B. Highly stretchable, recyclable, and fast room temperature self-healable biobased elastomers using polycondensation. Macromolecules, 2020, 53(22), 9847-9858.

12. Kallemets, K. Economic sustainability of Estonian shale oil industry until 2030. Oil Shale, 2016, 33(3), 272-289.

13. Veski, R., Veski, S. Aliphatic dicarboxylic acids from oil shale organic matter- 
historic review. Oil Shale, 2019, 36(1), 76-95.

14. Durand, B. Sedimentary Organic Matter and Kerogen: Definition and Quantitative Importance of Kerogen. Editions Technip., Paris, 1980.

15. Degtereva, Z., Fomina, A. Production of dibasic acids C4-C10 from oil shale kukersite. Acad. Sci. Est. SSR, 1959, 8(2), 122-136 (in Russian).

16. Pobul, L., Fomina, A. Purification and fractionation of mixtures of saturated dicarbonic acids obtained by the oxidation of kukersite kerogen. Acad. Sci. Est. SSR, 1962, 11(3), 203-211 (in Russian).

17. Fomina, A., Pobul, L., Degterjowa, S., Veski, R., Kirret, O., Nikopensius, I., Männik, A., Pärn, A., Poom, A., Murumets, K., Ulanen, J., Tänav, I., Kotov, A. Method for Processing Causticobiolites of the Sapropelite Type with an Oxidizing Agent. German Patent No. 2259502, 1974.

18. Fomina, A. S., Pobul, L. The deriving of dibasic aliphatic acids from a new raw material. Acad. Sci. Est. SSR, 1957, 6(2), 190-198.

19. Kogerman, P. N. Hundred years of the chemical investigation of an oil shale: the chemical constitution of the Estonian oil shale "Kukersite". In: Oil Shale and Cannel Coal. International Petroleum Conference. The Institute of Petroleum, Glasgow, 1938, 115-123.

20. Bajc, S., Amblès, A., Largeau, C., Derenne, S., Vitorović, D. Precursor biostructures in kerogen matrix revealed by oxidative degradation: oxidation of kerogen from Estonian kukersite. Org. Geochem., 2001, 32(6), 773-784.

21. Proskuryakov, V. A., Soloveichik, Z. V. Oxidation of oil shale by atmospheric oxygen. 1. Oxidation of an aqueous alkaline suspension of Gdov shales in an autoclave. Tr. Vsesoj. N. I. Instituta po Pererab. i Issl. Topl., 1961, 10, 64-80 (in Russian).

22. Proskuryakov, V. A., Soloveichik, Z. V. Oxidation of oil shale by atmospheric oxygen. 2. Oxidation of Gdov shales with continuous air supply. Tr. Vsesoj. N. I. Instituta po Pererab. i Issl. Topl., 1961, 10, 81-90 (in Russian).

23. Proskuryakov, V. A., Yakovlev, V. I., Kudrjukov, O. I. Oxidation of oil shale by atmospheric oxygen. 3. Oxidation of common Syrtian shales. Tr. Vsesoj. N. I. Instituta po Pererab. i Issl. Topl., 1962, 11, 20-27 (in Russian).

24. Kaldas, K., Preegel, G., Muldma, K., Lopp, M. Wet air oxidation of oil shales: Kerogen dissolution and dicarboxylic acid formation. ACS Omega, 2020, 5(35), 22021-22030.

25. Kolaczkowski, S. T., Plucinski, P., Beltran, F. J., Rivas, F. J., McLurgh, D. B. Wet air oxidation: a review of process technologies and aspects in reactor design. Chem. Eng. J., 1999, 73(2), 143-160.

26. Luck, F. A review of industrial catalytic wet air oxidation processes. Catal. Today, 1996, 27(1-2), 195-202.

27. Bhargava, S. K., Tardio, J., Prasad, J., Föger, K., Akolekar, D. B., Grocott, S. C. Wet oxidation and catalytic wet oxidation. Ind. Eng. Chem. Res., 2006, 45(4), 1221-1258.

28. Li, L., Chen, P., Gloyna, E. F. Generalized kinetic model for wet oxidation of organic compounds. AIChE J., 1991, 37(11), 1687-1697. 
29. Lin, S. H., Ho, S. J., Wu, C. L. Kinetic and performance characteristics of wet air oxidation of high-concentration wastewater. Ind. Eng. Chem. Res., 1996, 35(1), 307-314.

30. Sánchez-Oneto, J., Portela, J. R., Nebot, E., Martínez-de-la-Ossa, E. J. Wet air oxidation of long-chain carboxylic acids. Chem. Eng. J., 2004, 100(1-3), 43-50.

31. CRC Handbook of Chemistry and Physics, Internet Version 2005 (Lide, D. R., ed.), 2005. http://www.hbcpnctbasc.com

32. Kaldas, K., Preegel, G., Muldma, K., Lopp, M. Reactivity of aliphatic dicarboxylic acids in wet air oxidation conditions. Ind. Eng. Chem. Res., 2019, 58(25), 10855-10863. 